\title{
Modal Analysis of L Type Compressor Crankshaft
}

\author{
Xiaoyan Niu, Cong Chen, Linlin Shen, Erzhong Chen* \\ College of Civil Engineering and Architecture, Hebei University, Baoding, China \\ Email address: \\ 1060105@qq.com (Erzhong Chen) \\ ${ }^{*}$ Corresponding author
}

\section{To cite this article:}

Xiaoyan Niu, Cong Chen, Linlin Shen, Erzhong Chen. Modal Analysis of L Type Compressor Crankshaft. American Journal of Mechanical and Industrial Engineering. Vol. 3, No. 4, 2018, pp. 64-70. doi: 10.11648/j.ajmie.20180304.14

Received: August 27, 2018; Accepted: September 11, 2018; Published: October 11, 2018

\begin{abstract}
Reciprocating compressor is an important equipment in industrial production. The crankshaft turns the thrust of the compressor piston rod into torque, which is an important component of the compressor. When reciprocating compressor works, there will be various forms of vibration such as torsion and bending. Therefore, the study of the crankshaft vibration becomes particularly important. Analyze the modal analysis of L type compressor crankshaft by using the finite element simulation. The first six order natural frequency and the corresponding mode of vibration of the crankshaft are obtained. And analyze the influence of the hollow and solid on the natural frequency and mode of vibration of the crankshaft. The results show: With the increase of vibration order, the natural frequency of the crankshaft increase. The crankshaft deformation is mainly bending at low frequency. The deformation of crankshaft is mainly composed of bending and torsional vibration at higher frequency. Moreover, the ends of solid crankshafts are less restrained. Extend the service life and performance of the crankshaft and other parts of the compressor by increasing the strength and stiffness of the crankshaft's local materials. And increasing the fillet radius at the transition point are adopted to reduce the deformation and torsion of the crankshaft.
\end{abstract}

Keywords: Crankshaft, Finite Element Method, Modal Analysis

\section{Introduction}

Reciprocating compressors are important power equipment in production [1], such as petroleum, natural gas, chemical industry, electric power and so on. The compressor [2] is mainly operated by the piston connecting rod, and the crankshaft transforms the thrust on the connecting rod into the torsional torque. Correspondingly, the reciprocating straight motion of the piston is transformed into the circular motion of the crankshaft [3], and then the rotary torque is transmitted to the transmission system by the flywheel. There are many classifications of crankshafts. According to the structure form [4], it can be divided into integral type, combined type and disc type. The material can be divided into forged steel crankshaft and cast iron crankshaft according to the material. The main structure of the crankshaft consists of a front end, a crank, a connecting rod journal, a balancing block, a spindle neck and a rear end flange. The crankshaft is the core component of the compressor. The alternating load of periodic regularity varies with itself while working, which will lead to the crankshaft vibration in various forms, such as bending, twisting, etc. during the working process. Because this vibration usually occurs when the crankshaft is rotating at high speed, it becomes one of the important factors that cause compressor resonance [5]. The existence of resonance affects not only the service life of the crankshaft, but also the safety and stability of the compressor unit. Therefore, the modal analysis of the compressor crankshaft makes it not resonate in the normal work and is strengthened in the place of easy bending and torsion deformation. It will optimize the design of the crankshaft, and it is of great significance to the development of the compressor to the multi column and high speed.

The main failure modes of large compressor crankshaft are wear and fracture. The main reasons for the fracture are the lack of structural design strength, local stress concentration, material defects and operation errors. The statistical analysis of crankshaft failure shows that $80 \%$ is generated by bending fatigue [6-9]. These problems have been basically solved, but the fatigue fracture of crankshaft caused by torsional vibration has not been paid universal attention and solved, which has become a major factor restricting the development 
of reciprocating compressor to multi-row and high speed. The modal analysis of crankshaft is the analysis of vibration characteristics, and provides the basis for vibration fault analysis and structural dynamic characteristics optimization design [10]. Therefore, the modal analysis of the crankshaft, so as to grasp the vibration characteristics of the crankshaft structure, the natural frequency corresponding to each mode of vibration, for the crankshaft design needs to consider the vibration characteristics have important reference value. In general, when the number of compressors is greater than or equal to the sixth order, the main failure mode is the resonance between the crankshaft and other parts under periodic dynamic load, which will lead to the rapid increase of the dynamic stress on the crankshaft and the premature fatigue failure of the crankshaft. The natural frequency and rotational speed of the crankshaft are important references for judging whether the crankshaft will resonate with other parts or not. However, the compressor crankshaft is very difficult to solve by analytical formula because of its complex structure and shape. Empirical formulas such as Carter formula, Ker Wilson formula and approximate calculation method for discretizing complex crankshaft structures are generally used [11]. In recent years, with the development of computer simulation software, many finite element software have sprung up. For example, ALGOR FEAS finite element analysis software, COMOS/M finite element analysis software, MSC/NASTRAN finite element analysis software, ANSYS finite element analysis software and so on, more and more compressor crankshafts begin to use finite element analysis to calculate the rotational inertia and torsional stiffness of the concentrated mass (corresponding to the relative shaft end).

The research of crankshaft modal analysis has been continuing by scholars both at world. LV Rui [12] and other modal analysis of the engine crankshaft of the racing car, provides a basis for the design of the crankshaft. Liu Lingchang [13] and others carried out modal analysis to the crankshaft of six cylinder compressor. Through the analysis of the harmonic response of the crankshaft, the resonant frequency and amplitude of the crankshaft were obtained, which provided the basis for the design of the crankshaft. Chen Ran [14] and others analyzed the crankshaft of the internal combustion engine. According to its natural frequency and vibration mode, the structural optimization and improvement suggestions were put forward. Scholars have done a lot of research on modal analysis, but lack of research on different structural structures of crankshafts. The influence of hollow and solid on the natural frequencies and vibration modes of crankshaft $\mathrm{L}$ crankshaft is studied in this paper.

\section{The Establishment of the Model}

L type crankshaft of reciprocating compressor is chosen as the research object in this paper. Two models of hollow and solid are set up in the main shaft neck in the crankshaft modeling. The hollow section is a cylinder with a length of $136 \mathrm{~mm}$ and a radius of $17.5 \mathrm{~mm}$ as the hollow crankshaft. The main size of the crankshaft is the full length of the crankshaft $483 \mathrm{~mm}$, and the diameter of the spindle neck is $60 \mathrm{~mm}$. Because of the complexity of ANSYS software modeling, establish the three-dimensional solid model of crankshaft by using Pro/E software. Then the threedimensional solid model of crankshaft built in Pro/E is directly imported into ANSYS software for modal analysis.

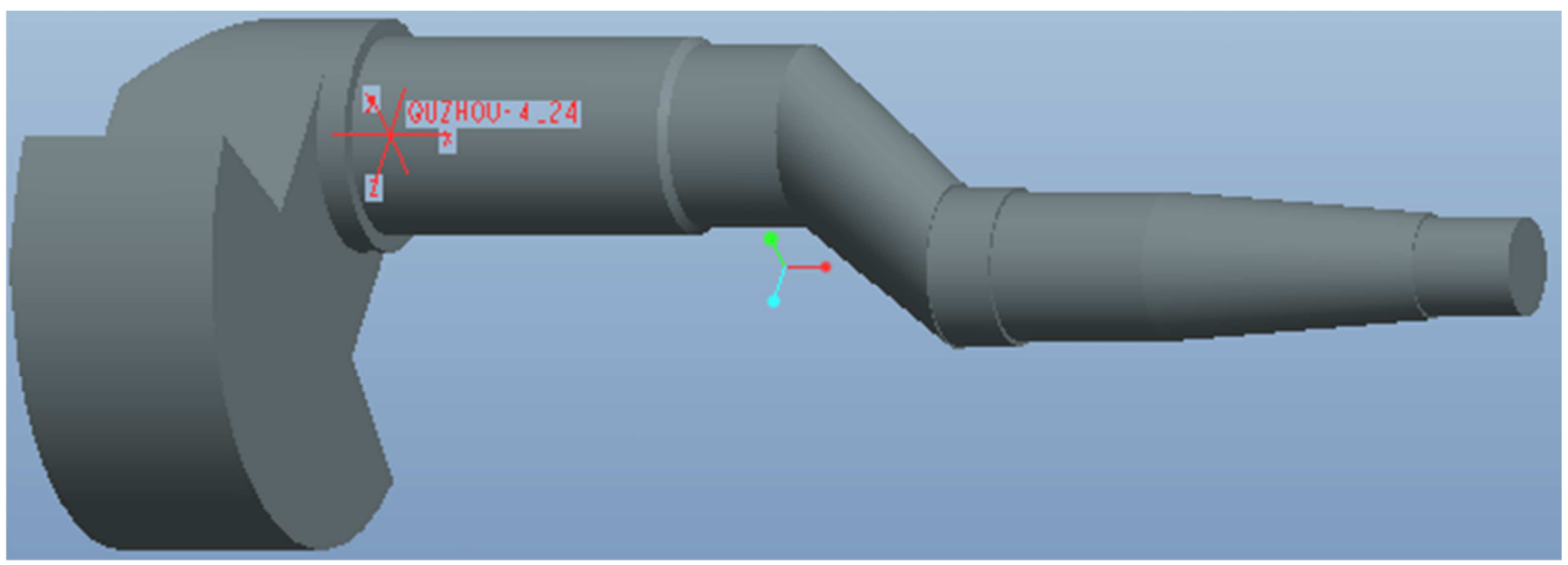

Figure 1. The solid crankshaft.

Before modal analysis, the material performance parameters of the crankshaft are set as follows: the density is $7300 \mathrm{~kg} / \mathrm{m} 3$, the elastic modulus is $169 \mathrm{GPa}$, and the Poisson's ratio is 0.286 . In the modal analysis, considering the actual working condition of the compressor crankshaft in this paper, the fixed end constraint is applied to the left end of the crankshaft, and the radial constraint along the direction of the $\mathrm{X}$ axis is applied to the front end. Mesh generation and constraints are applied after the import model, and finally modal analysis is carried out. 


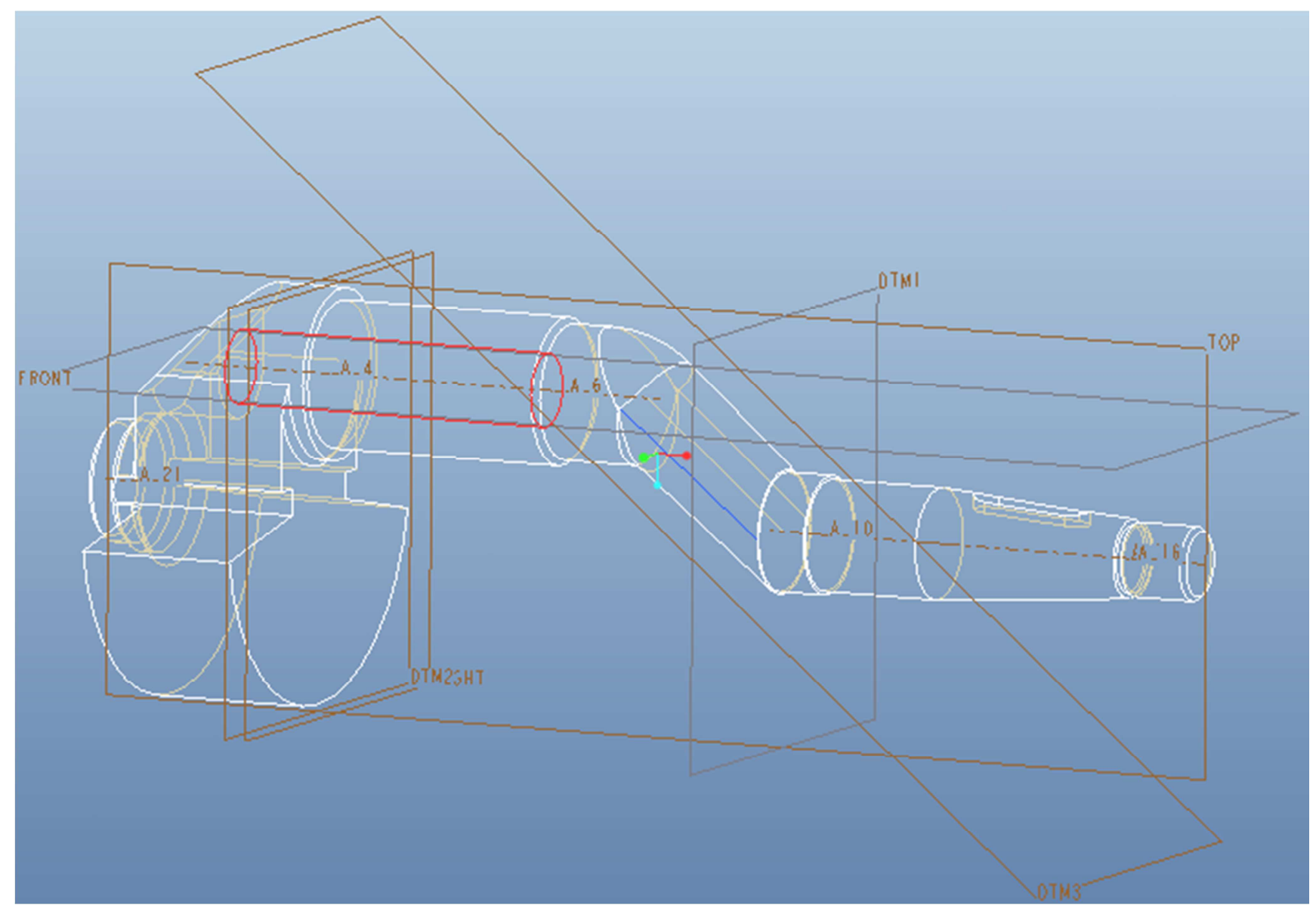

Figure 2. The hollow crankshaft.

\section{Calculation Principle and Modal Analysis of Crankshaft}

\subsection{Calculation Principle}

In this paper, the crankshaft modal analysis is carried out based on the principle of finite element. Finite Element Method is a method to solve the boundary value problems of partial differential equations. The complex domain is decomposed into a finite number of simple subdomains, which is called finite element. In practical engineering problems, because the actual situation is complex and the shape of the structure to be analyzed is complex, this method of solving the complex domain separately actually includes all the solving methods. The solution of each subdomain is estimated by the conditions satisfied by each subdomain, so the solution is approximate solution. Although it is an approximate solution, it is difficult to obtain an accurate solution for the actual working conditions, and the design and production only need to meet the accuracy requirements, so the finite element method can solve a wide range of Engineering problems.

The concrete ideas of the finite element method are as follows:

(1) Discretization

The decomposition of complex structures into combinations of simple structures is discretization. After decomposition, the elements are interconnected by nodes, so the nature of the element is expressed in the form of the number and distribution of nodes in the element, which is also related to the final calculation accuracy. At the same time, the more dense the element is, the more accurate the result will be, and the more consistent with the actual situation.

(2) Displacement mode

Using finite element method to solve mechanical problems can be divided into three types. Displacement method: the displacement method is the solution to the displacement of nodes in the element as an unknown quantity. Force method: node force as unknown quantity is the force method. Hybrid method: In order to satisfy the calculation convenience, the displacement is taken as the unknown quantity to solve part of the problem, and the node force is taken as the solution of the hybrid method. Displacement method is easy to calculate by computer software. In this paper, displacement method is used to solve it. When the displacement method is used, the physical quantities such as displacement, stress and strain in the element body can be expressed by the displacement of the node. At the same time, the displacement of the node in the element can be described by the approximate function of the original function. First solve the problem. 
(3) Mechanical properties

Mechanics property is to find the relationship between the force and displacement of the element nodes according to the actual material property, size, structural parameters, number of nodes and so on. Usually, it is necessary to connect them by geometric equation and physical equation, and finally get the element stiffness matrix.

(4) Equivalent nodal force

When the structure is discretized, it becomes an independent element. It is assumed that the mechanism of interaction between elements is that the force is transmitted through nodes. In fact, when the force passes from one element to another, there must be a common edge between the elements. Therefore, it is necessary to transform the surface force and the body force which can affect the calculation results on the boundary of the element into the equivalent force on the node.

The modal analysis of crankshaft by finite element method can be simplified to solve the two order nonhomogeneous equation. The equation is

$$
[\mathrm{M}]\{\ddot{\mathrm{q}}\}+[\mathrm{C}]\{\dot{\mathrm{q}}\}+[\mathrm{K}]\{\mathrm{q}\}=\{\mathrm{f}\}
$$

Among them, $\{\mathrm{q}\}$ is a displacement matrix; is a velocity matrix; is an acceleration matrix, $[\mathrm{M}]$ is a mass matrix; $[\mathrm{C}]$ is a damping matrix, $[\mathrm{K}]$ is a stiffness matrix, $\{\mathrm{f}\}$ is a excitation force matrix.

The structural damping of the crankshaft is very small. It's influence on the natural frequencies and modes is negligible. So the crankshaft structure has no damping free vibration differential equation. The equation is:

$$
[\mathrm{M}]\{\ddot{\mathrm{q}}\}+[\mathrm{K}]\{\mathrm{q}\}=\{\mathrm{f}\}
$$

Again, $\{f\}=0$. The upper formula becomes a two order homogeneous linear differential equation with constant coefficients. The $2 \mathrm{n}$ algebraic equation of the natural frequency can be obtained By solving the upper equation.

When the structure vibrate at a certain natural frequency, that is, $\{\ddot{\mathrm{q}}\}=\{\phi\}$. it is brought into the upper form. Available:

$$
\left([\mathrm{K}]-\omega^{2}[\mathrm{M}]\right)\{\psi\}=\{0\}
$$

$\{\psi\}=\{0\}$ is one of the solutions, which indicates that all nodes of the structure are at rest. Therefore, if the non zero solution is obtained, it must be satisfied: $\operatorname{det}\left([\mathrm{K}]-\omega^{2}[\mathrm{M}]\right)=0$, which is the characteristic equation of vibration. And the square root of the eigenvalues is the natural frequency of the free vibration of the structure [15]. The eigenvector $\left\{\psi_{i}\right\}$ is the modal vector corresponding to $\omega_{i}$, so the solution of natural frequency is transformed into the problem of solving eigenvalues by linear algebra.

\subsection{Mode Analysis}

The first six modes of the hollow and solid crankshaft models are compared and analyzed in this paper, and the natural frequency of each mode are shown in Table 1. It is found that there is not much correlation about the first six natural frequency of crankshaft whether the spindle neck is hollow through comparison. There has been a trend of change in general. With the increase of mode of vibration order, the natural frequency of crankshaft increase. This is because the energy required to excite higher order vibrational loads decreases with the increase of order. The number of nodes of higher order vibration is more than that of low order vibration, so it is not easy to be excited than low order. Therefore, the crankshaft has the lowest natural frequency in the first mode.

Table 1. Natural frequency of each order mode.

\begin{tabular}{lll}
\hline Order & Hollow natural frequency $(\mathrm{Hz})$ & $\begin{array}{l}\text { Solid natural frequency } \\
(\mathbf{H z})\end{array}$ \\
\hline 1 & 657.85 & 657.53 \\
2 & 674.53 & 677.32 \\
3 & 1128.9 & 1157.6 \\
4 & 1525.3 & 1557.0 \\
5 & 1884.8 & 1937.3 \\
6 & 2802.0 & 2911.3 \\
\hline
\end{tabular}

The maximum mode of vibration of the two crankshaft models is shown in Table 2. It can be seen that the mode of vibration of the hollow crankshaft is slightly larger than that of the solid crankshaft. It shows that the restraint at both ends is less than that for solid crankshaft, so the solid crankshaft is more reasonable. It shows that the restraint at both ends is less loss to the solid crankshaft than the hollow crankshaft. The natural frequency and the corresponding mode of vibration of both the solid crankshafts and the hollow crankshafts are universal. Taking the hollow crankshaft as an example, the first 6 modes of the crankshaft are analyzed.

Table 2. The maximum mode of vibration of two crankshaft models.

\begin{tabular}{lll}
\hline Order & $\begin{array}{l}\text { The hollow natural } \\
\text { deformation }(\mathbf{m m})\end{array}$ & $\begin{array}{l}\text { The solid natural } \\
\text { deformation }(\mathbf{m m})\end{array}$ \\
\hline 1 & 18.225 & 17.651 \\
2 & 18.5 & 18.024 \\
3 & 18.482 & 17.465 \\
4 & 21.486 & 20.619 \\
5 & 17.902 & 16.525 \\
6 & 23.421 & 25.07 \\
\hline
\end{tabular}

The maximum mode of vibration of the two crankshaft models is shown in Table 2. It can be seen that the mode of vibration of the hollow crankshaft is slightly larger than that of the solid crankshaft. It shows that the restraint at both ends is less than that for solid crankshaft, so the solid crankshaft is more reasonable. It shows that the restraint at both ends is less loss to the solid crankshaft than the hollow crankshaft. The natural frequency and the corresponding mode of vibration of both the solid crankshafts and the 
hollow crankshafts are universal. Taking the hollow crankshaft as an example, the first 6 modes of the crankshaft are analyzed.

As shown in figure 3-8. The first mode of vibration is the radial swing of the crankshaft around the $Z$ axis, resulting in larger vibration displacement at the right end of the crank arm. The two order mode of vibration is a bending vibration of the crankshaft in the XOZ plane, where the larger part of the crank arm is at the right end and the crank. The three order mode of vibration is flexural vibration in the XOY plane, resulting in larger displacement in the balance block and the right end of the crank arm. The four order mode of vibration is the two bending vibration in the $\mathrm{XOZ}$ plane, resulting in larger displacement at the connection between the crank and the spindle. However, the displacement increases greatly compared to the three order mode of vibration. The vibration form of the crankshaft is changed into torsional oscillation in the five order mode of vibration, and the deformation amount decreases greatly. The six order mode of vibration deformation is larger than that of the five order mode of vibration. With the increase of the order, the natural frequency of crankshaft is higher and higher, and the form of vibration combination becomes more and more complex. Starting from the five mode of vibration, the two or more than two forms of vibration in the form of bending, torsion and expansion are the results. And the deformation is also much larger.

From the analysis results, the lower axial vibration mode (the first 6 orders) produces larger axial displacement of the crank arm. At the same time, it produces larger bending deformation at the transition point of the crank. Therefore, bending cracks are easy to occur due to free vibration. Because the crankshaft is not loaded laterally, torsional resonance becomes the main form of crankshaft failure.

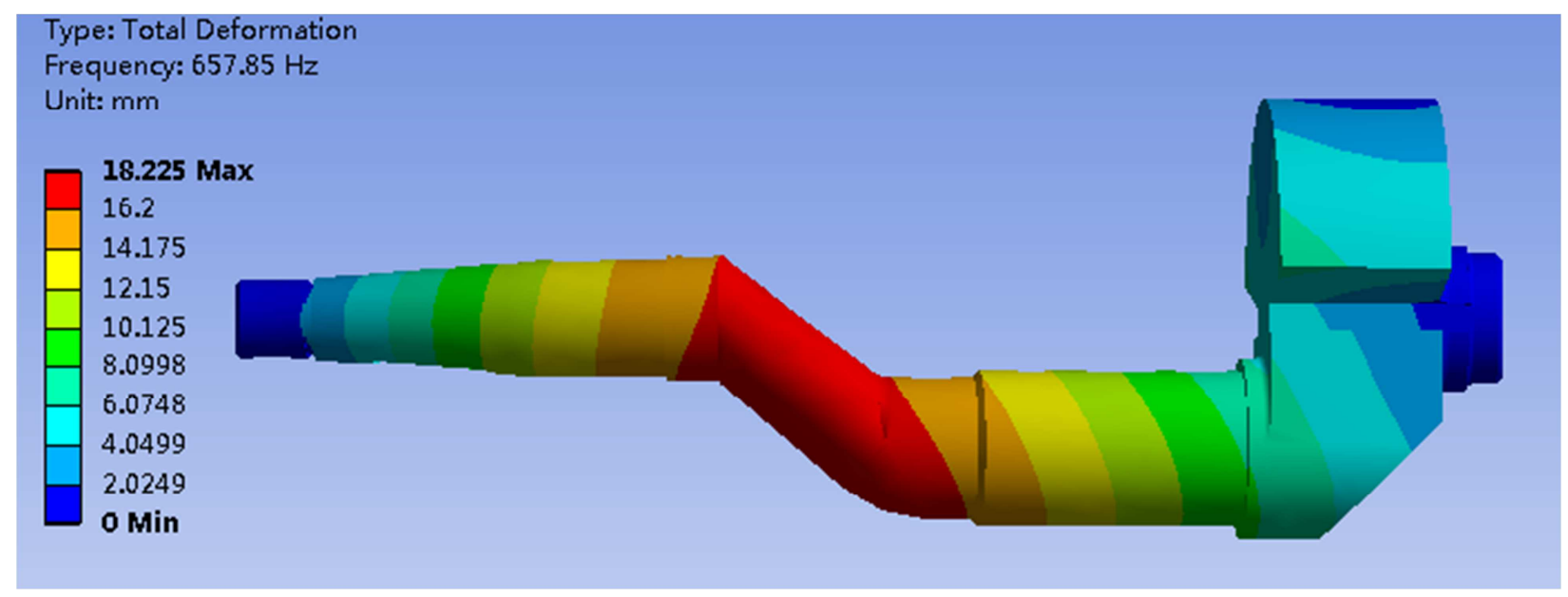

Figure 3. 1 order mode diagram.

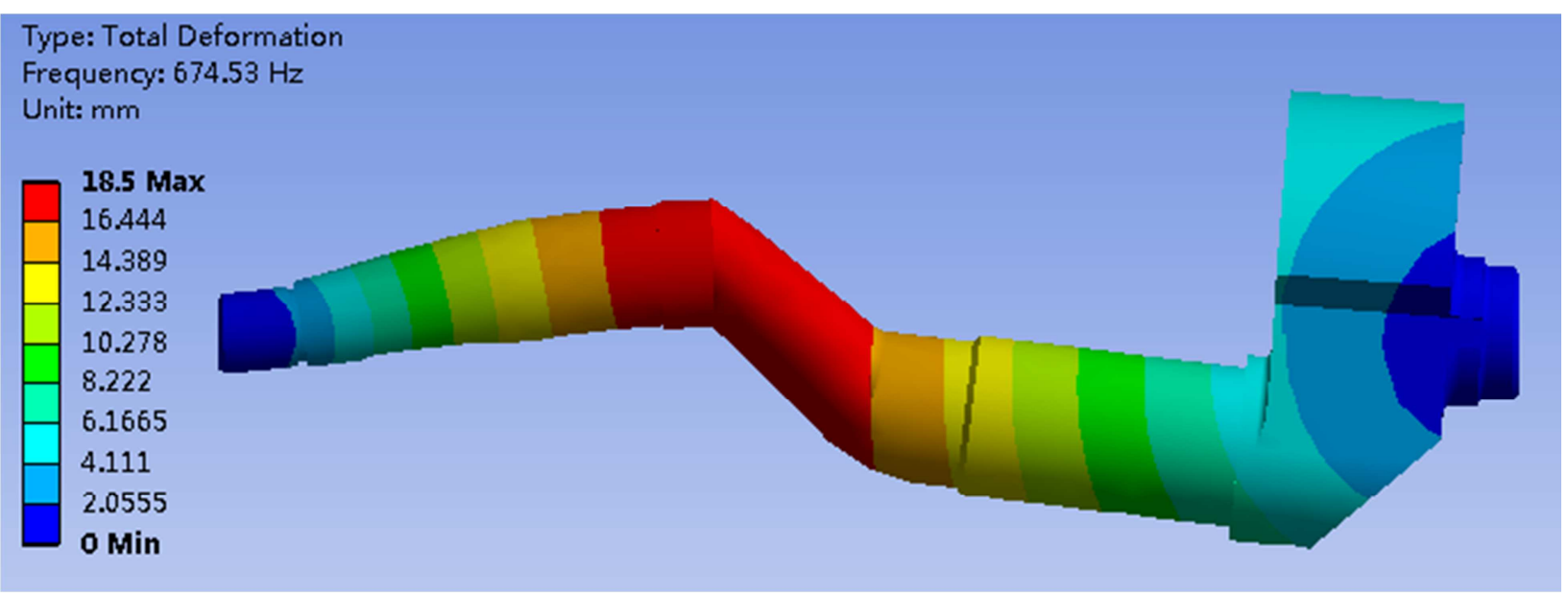

Figure 4. 2 order mode diagram. 


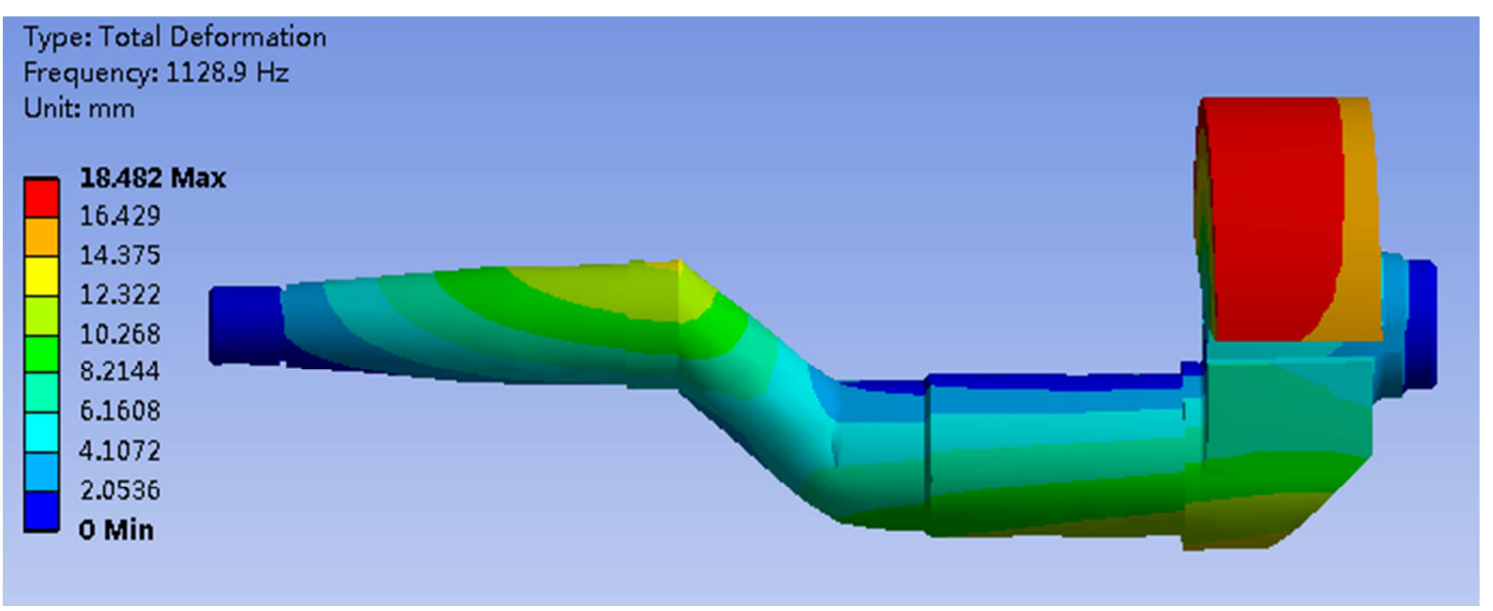

Figure 5. 3 order mode diagram.

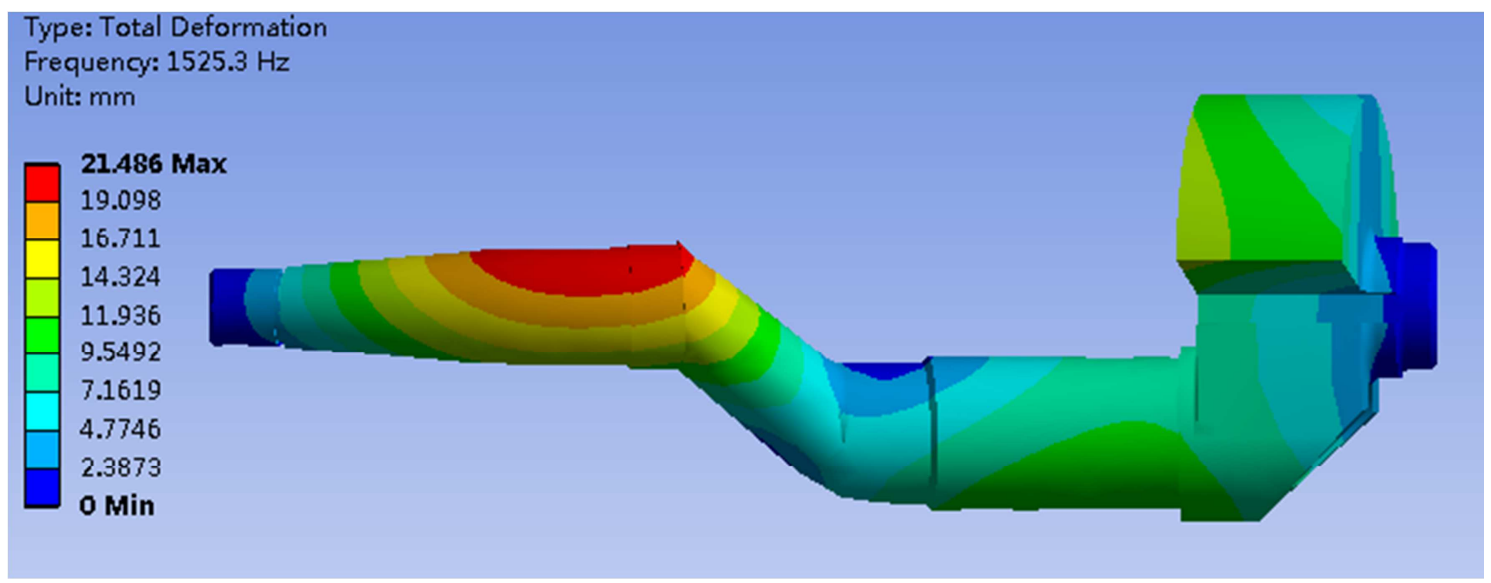

Figure 6. 4 order mode diagram.

The main deformation of the crankshaft is bending and torsional deformation, and with the increase of the order and frequency, the deformation increases gradually, the form of deformation is more complex, and the dangerous deformation may be formed. Moreover, the mode of vibration the solid crankshaft under the same load condition is smaller than the hollow crankshaft, which is a more reasonable structure. In a certain frequency range, the distortion of the radial wave along the axes of the axes may cause the two fixed ends of the crankshaft to bear large alternating loads. Therefore, the strength and stiffness of supporting parts at both ends should be considered appropriately in material selection. The six order vibration pattern obtained from the analysis shows that the main parts of the crankshaft deformation are at the crank arm and crank joint. This should also be fully considered in design, which can be improved by increasing the machining quality and increasing the radius of transition fillet. In addition, fatigue at the corner of crank and crank is prone to fatigue, and attention should also be paid to design.

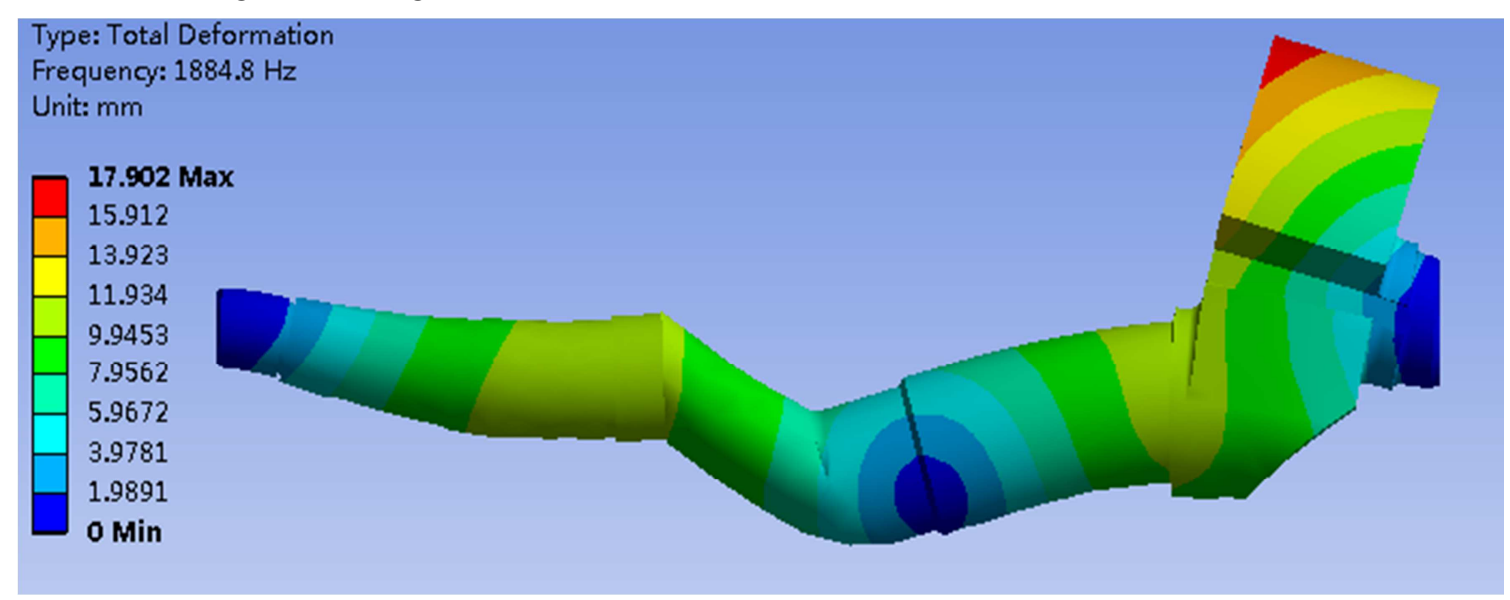

Figure 7.5 order mode diagram. 


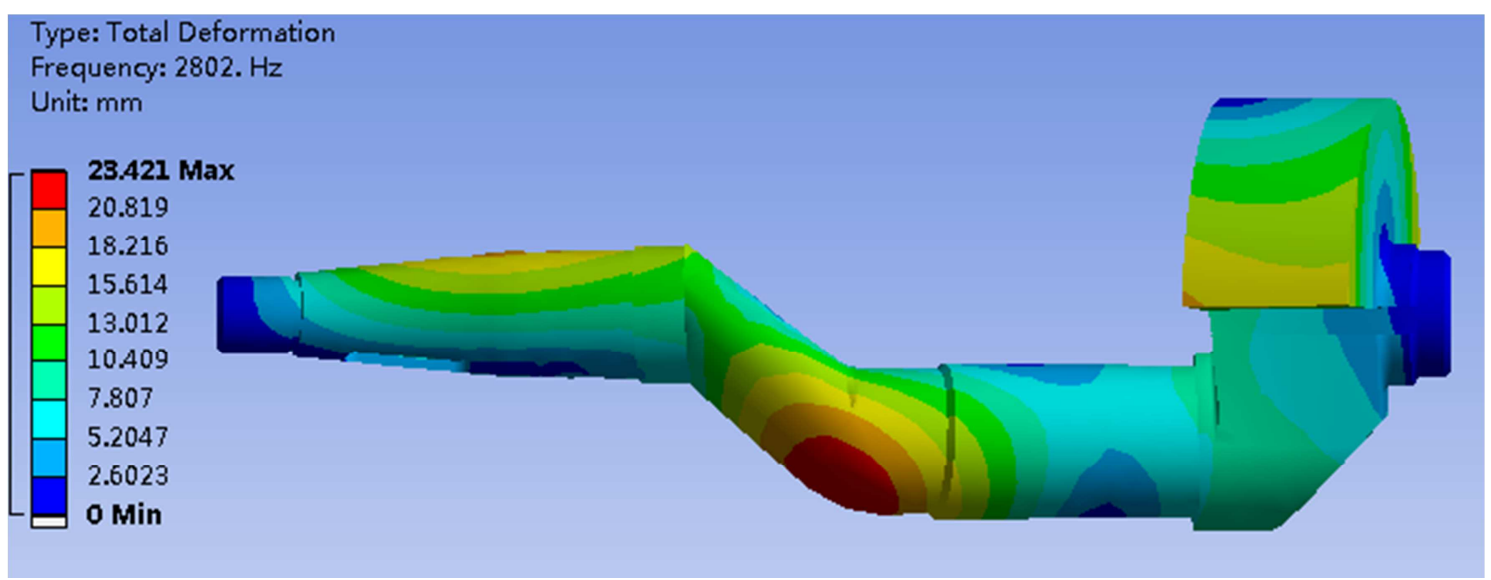

Figure 8. 6 order mode diagram.

\section{Conclusion}

1. It is found that the deformation of the right end of the crankshaft is larger, the natural frequency increases with the increase of the order number. And the crankshaft is deformed at the lower order of frequency. The bending and torsional vibration are the main deformation forms at the higher order frequency. The deformation of the crank connection and the crank is large, and fatigue fracture is easy to occur. The solid crankshaft has smaller vibration modes compared with the hollow crankshafts in all cases, and the material loss of the solid crankshaft is smaller by both ends. So the solid crankshaft is more reasonable.

2. In a certain frequency range, the distortion of the radial wave along the axes of the axes may cause the two fixed ends of the crankshaft to bear large alternating loads. Therefore, the strength and stiffness of supporting parts at both ends should be considered appropriately in material selection. The main parts of the crankshaft deformation are at the crank arm and crank joint. It can be improved by increasing the machining quality and increasing the radius of transition fillet.

\section{Acknowledgements}

This study was supported by National Natural Science Foundation of China (grant no. 11502065 and 11572109), Key projects of science and technology research in Colleges and Universities of Hebei Province (grant no. ZD2016146) and the Natural Science Foundation of Hebei Province (grant no. A2016201198).

\section{References}

[1] Changchun Shan. Discussion on Faults and Prevention Methods of Reciprocating Compressor Operation [J]. China Strategically Emerging Industries, 2018 (16):186.

[2] Changling Liu, Jianyi Chen, Qingping Li, Chen Qiu, Xiaolan Luo. Modal Analysis and Harmonic Response Analysis of SixCylinder Compressor Crankshaft Based on ANSYS [J]. Fluid machinery, 2012, 40 (08):17-21+26.
[3] Changling Liu, Xiaolan Luo. Modal Analysis and Harmonic Response Analysis of Six-Cylinder Compressor Based on ANSYS [J]. Machinery Design \& Manufacture, 2013 (03):2629.

[4] Haifeng Zhang. Research on Crankshaft Characteristics of Large Compressors [D]. Nanjing University of Science and Technology, 2005.

[5] Liansheng Li, Bing Tang, Le Wang. Finite Element Analysis of Reciprocating Compressor Crankshaft under Variable Working Conditions [J]. Fluid machinery, 2011, 39 (12):14-17.

[6] Bin Zhao. Modal analysis and fatigue analysis of compressor crankshaft [J]. Petrochemical equipment, 2008, 9 (5).

[7] Liu Mingsheng. Reliability Analysis and Fatigue Strength Design of Crankshaft [J]. Equipment Manufacturing Technology, 2014 (03): 96-99+102.

[8] Ye Xiaoyan, Jiang Xiaoping, Xu Jianqiang, Hu Jingning. Development of fatigue reliability design software for reciprocating pump crankshaft $[\mathrm{J}]$. Journal of Agricultural Machinery, 2008 (06): 94-97+72.

[9] Huang Shiwei, Huang Wei. Reliability study of crankshaft fatigue strength $[\mathrm{J}]$. equipment manufacturing technology, 2008 (07): 22-24.

[10] Zhuo Wu. Finite element modal analysis of four-cylinder engine crankshafts based on Pro/E and ANSYS Workbench [J]. New technologies and processes, 2014, 4, 89-91.

[11] Peng Li. Finite element calculation of crankshaft rotational inertia and torsional stiffness for reciprocating compressors $[\mathrm{J}]$. Compressor technology, 2017, 6 (266), 24-27.

[12] Tao Chen. 6HS-F analysis and optimization design of dynamic balance high-speed crankshaft torsional vibration [D]. Shenyang University of Science and Technology, 2016.

[13] Xiaoling Yu, Bingyan Yu, Quanke Feng. Crankshaft vibration analysis of large piston compressor (1) -- modal analysis [J]. Compressor Technology, 2011 (02):10-12+23.

[14] Ran Chen, Yonghong Cao, Huadong Sun. Modal Analysis of Crankshaft of Internal Combustion Engine Based on ANSYS [J]. Coal Engineering, 2015, 47 (04):108-109+113.

[15] Rui Lv, Dongjian Zeng, Xiaoyang Yu, Longping Zhang. Finite Element Modal Analysis of V8 Engine Crankshaft Based on ANSYS Workbench [J]. Mechanical Design and Manufacturing, 2012 (08): 11-13. 